\title{
Analysis of segmentation methods for acne vulgaris images. Proposal of a new methodology applied to fluorescence images
}

\author{
Moncho Santonja, María ${ }^{a}$; Sanz Alamán, María Begoña ${ }^{a}$; Defez García, Beatriz ${ }^{a}$; \\ Lengua Lengua, Ismael ${ }^{\text {; }}$ Peris-Fajarnés, Guillermo ${ }^{\text {a* }}$ \\ a Centro de Investigación en Tecnologías Gráficas, Universitat Politècnica de València \\ *gperis@upv.es;
}

\begin{abstract}
Acne vulgaris is one of the most common human pathologies worldwide. Its prevalence causes a high healthcare expenditure. Acne healthcare costs and effects on individuals' quality of life lead to the need of analysing current acne evaluation, treatment and monitoring methods. One of the most common ones is manual lesion counting by a dermatologist. However, this technique has several limitations, such as time spent. That is the reason why the development of new computer-assisted techniques are needed in order to automatically count the acne lesions. Nonetheless, the first step is automatic acne lesion detection on the skin of patients. The aim of this work is to propose a new methodology to solve the acne images segmentation problem, so that the implementation of a system for automatic counting is possible. The results would be a decrease in both time spent and diagnosis errors. With this objective, after doing a systematic review on the state of the art of acne images segmentation methods, fluorescence images of the face of acne patients are obtained. This image modality enhances visualization of the acne lesions. Finally, using the fluorescence images, a segmentation algorithm is implemented in MATLAB.
\end{abstract}

Keywords: image segmentation, acne vulgaris, MATLAB, fluorescence imaging, machine learning, image processing. 


\begin{abstract}
Resumen
El acné vulgar es una de las patologías más comunes en el ser humano. Su prevalencia supone un elevado coste económico, el cual, junto con el impacto en la calidad de vida de los pacientes, conlleva la necesidad de analizar los métodos actuales de evaluación, tratamiento y seguimiento del acné. Entre los métodos de evaluación y seguimiento más comunes se encuentra el recuento manual, por parte del dermatólogo, de las lesiones. Esta técnica, sin embargo, presenta limitaciones tales como el tiempo necesario para llevarla a cabo correctamente. Por este motivo, surge la necesidad de desarrollar nuevas técnicas asistidas por ordenador que permitan realizar el recuento de manera automática. Para ello, es necesario, en primer lugar, la detección automática de las lesiones de acné en la piel del paciente. El presente estudio propone una nueva metodología para resolver el problema de la segmentación de imágenes de acné, que permita el desarrollo de un sistema de conteo automático, para reducir el tiempo de consulta y los errores diagnósticos. Con este fin, tras realizar una revisión sistemática para conocer el estado del arte en técnicas de segmentación propuestas para acné vulgar, se obtienen imágenes de fluorescencia del rostro de individuos con esta patología, pues dicha modalidad de imagen facilita la detección de las lesiones. Con las imágenes se genera un algoritmo de segmentación utilizando el software MATLAB.
\end{abstract}

Palabras clave: segmentación de imágenes, acné vulgar, MATLAB, imágenes de fluorescencia, aprendizaje automático, procesado de imágenes.

\title{
1. Introduction
}

Acne vulgaris is an inflammatory chronic disease of pilosebaceous units - a pilosebaceous unit is formed by all the hair follicles related to the same sebaceous gland. The main affected regions are face, neck, chest and back. Clinical manifestations are seborrhoea or overproduction of sebum, the presence of non-inflammatory and inflammatory lesions on skin (open and closed commedos, and pustules and papules, respectively), and scars (Williams, Dellavalle, \& Garner, 2012). It is the most common dermatological pathology worldwide (Zouboulis, 2014). 85\% of adolescents suffer from acne (Ramli, Malik, Hani, \& Jamil, 2012). 
In order to monitor and treat acne properly, a precise and reliable method to establish acne severity is needed (Becker, Wild, \& Zouboulis, 2017). Currently there is a wide range of acne grading systems, which shows the lack of a global standard. These systems can be divided into two groups: those based on manual lesion counting and the ones that use a model photography (Ramli et al., 2012; Becker et al., 2017) Several studies (Lucky et al., 1996; Becker et al., 2017) have proved lesion counting to be an objective and reliable method.

Beyond classical methodologies for the evaluation and monitoring of acne vulgaris, new computer-based techniques - sometimes applied to new image modalities, such as fluorescence images or polarized photograpy — have appeared to solve current limitations. These limitations include time spent and human errors and lead to an increase of economic costs. The aim of this study is to develop a new methodology to automatically count acne lesions by implementing a segmentation algorithm on fluorescence images. To achieve this, it is necessary to analyse the state of the art on segmentation methods applied to acne vulgaris images, so the first original contribution of this work is the first systematic review for acne images segmentation methods.

\subsection{Fluorescence images}

One of the characteristics of acne is the colonization of hair follicles by bacteria Propionibacterium acnes (P. acnes) (Williams et al., 2012; Zouboulis, 2014). Several studies (Patwardhan et al., 2017; Xu et al., 2018) have shown that substances secreted by $P$. acnes called porphyrins are the cause of acne lesions fluorescence. Porphyrins absorbe ultraviolet (UV) light and emit red fluorescence in response (Borelli et al., 2006; Youn, Kim, Lee, Kim, \& Park, 2009). Consequently, it is possible to enhance the visualization of acne lesions using fluorescence images of the skin of acne patients.

\section{Systematic review}

To conduct a systematic review on acne images segmentation methods, an adapted PRISMA (Preferred Reporting Items for Systematic reviews and Meta-Analyses) (Liberati et al., 2009) standard was used. The analysis includes all studies published until April 2019 and explores four databases: Scopus (https://www.scopus.com/home.uri), PubMed Central (https://www. ncbi.nlm.nih.gov/pmc/), Web of Science (https://www.recursoscientificos.fecyt.es/) and Google Scholar (https://scholar.google.es/). PICO (Population, Intervention, Comparison and Outcome) model was used. With the 
selected inclusion and exclusion criteria, a total of 20 studies were included in the systematic review.

The review shows that current segmentation methods for acne vulgaris images can be divided into two groups: those algorithms based on classical image processing techniques (Ramli, Malik, Hani, \& Yap, 2011a; Chen, Chang, \& Cao, 2012; Khongsuwan, Kiattisin, Wongseree, \& Leelasantitham, 2012; Humayun, Malik, Belhaouari, Kamel, \& Yap, 2012; Liu \& Zerubia, 2013; Min, Kong, Yoon, Kim, \& Suh, 2013; Malik, Humayun, Kamel, \& Yap, 2014; Chantharaphaichi, Uyyanonvara, Sinthanayothin, \& Nishihara, 2015; Alamdari, Tavakolian, Alhashim, \& Fazel-Rezai, 2016; Kittigul \& Uyyanonvara, 2016; Budhi, Adipranata, \& Gunawan, 2017; Maroni, Ermidoro, Previdi, \& Bigini, 2017) - they consist of a series of steps or operations that have to be applied to an image, for instance color space transformations or contrast modifications. The other group refers to machine learning algorithms (Fujii et al., 2008; Ramli, Malik, Hani, \& Yap, 2011b; Madan, Dana, \& Cula, 2011; Arifin, Kibria, Firoze, Amini, \& Yan, 2012; Chang \& Liao, 2013; Malik et al., 2014; Khan, Malik, Kamel, Dass, \& Affandi, 2015; Alamdari et al., 2016). There is no preference between one group or another, since nowadays both types of methodologies are being proposed by research groups. In addition, there is a lack of uniformity in the evaluation of results for each study, which makes the comparison of these segmentation methods difficult.

In order to perform segmentation, different image modalities are used, but conventional photographs are the most common modality. Fluorescence images are used in only two studies (Son, Han, Jung, \& Nelson, 2008; Khongsuwan et al., 2012).

An analysis of limitations for each study included in the systematic review showed that algorithms based on classical image processing techniques cannot be totally automatized, mainly because there are some parameters that need to be manually adjusted (Son et al., 2008; Humayun et al., 2012; Budhi et al., 2017; Maroni et al., 2017). That is why in the present work machine learning algorithms are chosen for the implementation of the proposed methodology.

Moreover, there is a research gap on segmentation methods for different image modalities. As previously reported, there are only two methodologies proposed for fluorescence images. In this study the authors hypothesise that fluorescence imaging can be a useful modality to segment and automatically count acne lesions, since it is easy to capture the images and lesions are visually enhanced. 


\section{Materials and Methods}

Before the implementation of the algorithm, fluorescence images are obtained in the laboratories of Centro de Investigación en Tecnologías Gráficas. These are photographies of the face of mild acne patients. Figure 1 shows two of the obtained images.

Two different lamps were used — Wood's lamp and a LED lamp — both emitting UV light. The capture sensor was a standard RGB camera which corresponds to the model of the iPhone $\mathrm{X}$ smartphone. In order to avoid the most common interferences in this kind of images, two highpass filters from UQG Optics were used - cutoff wavelengths of $515 \mathrm{~nm}$ (OG-515) and $530 \mathrm{~nm}$ (OG-530).
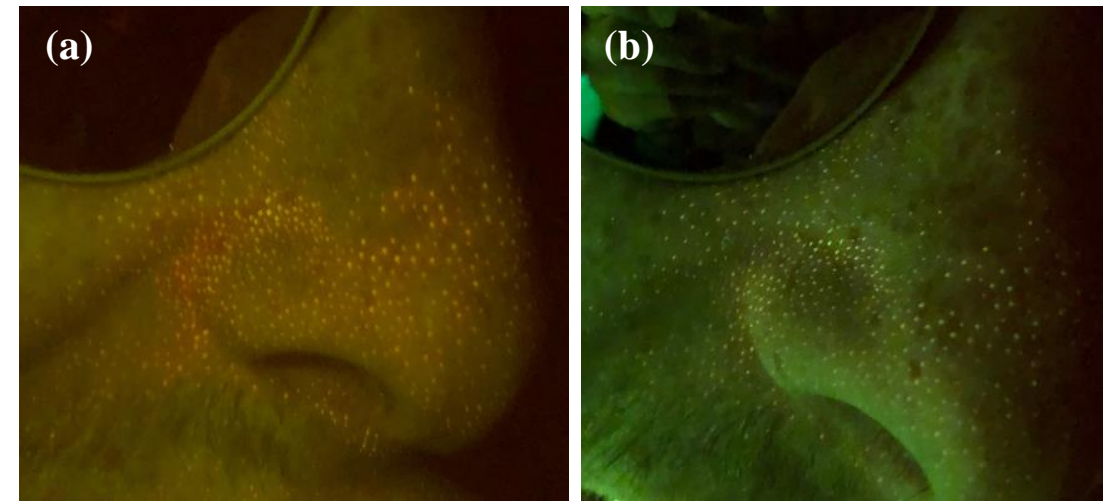

Fig 1. Two of the images captured in the laboratory, for the same subject. (a) Image obtained with a LED lamp and $O G-530$ filter. (b) Image obtained with Wood's light and $O G-515$ filter

The segmentation algorithm was implemented using MATLAB R2018b and is based on kmeans clustering with automated selection of the desired cluster - the one which contains lesion pixels. The k-means algorithm allows the method to detect acne points without human intervention.

\section{Results}

Figure 2 shows the input and output images for one of the fluorescence images used in the implementation of the segmentation algorithm. This algorithm segments the image in order to detect acne lesions and finally demarks and counts these lesions automatically. 

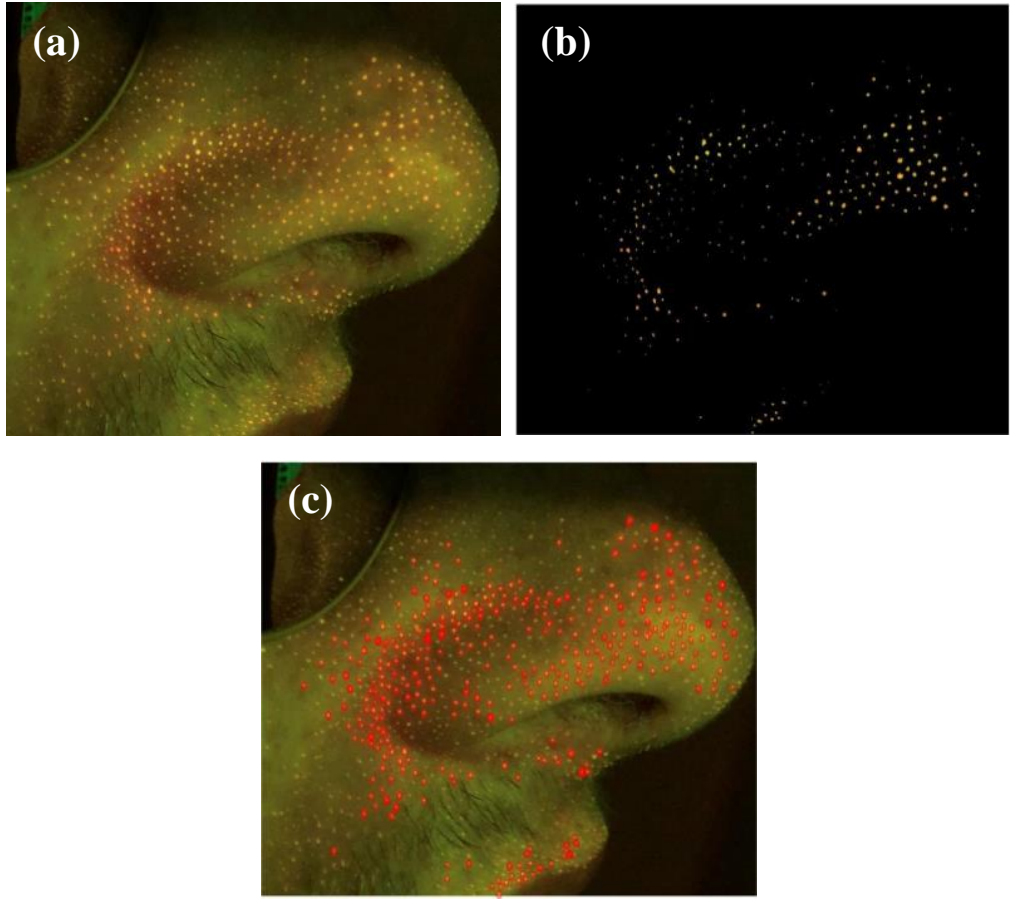

Fig 2. (a) Fluorescence image obtained with LED light and OG-515 filter. (b) Result of segmentation for image (a). (c) The algorithm demarcates detected acne lesions on input image. Another output is the number of detected lesions. In this case it was 477.

\subsection{Future work}

The results of the validation of the algorithm, as well as the code details, will be reported in a future publication. Although it has been shown, through visual qualitative inspection, that the method distinguishes healthy skin and acne points properly, it is necessary to objectively evaluate that. Concretely, the algorithm ability to distinguish between true acne lesions — red points - and light reflection — white points - has to be quantified. Sensitivity, specificity, precission and accuracy will be calculated, using manual segmentation as ground truth. 


\section{Conclusions}

Automated counting of acne lesions has been proposed to solve current limitations of evaluation and monitoring methods for acne vulgaris. Although the new methodology is yet to be validated, it is clear that the use of machine learning algorithms such as k-means enables clinicians to objectively and quickly evaluate the severity of acne. Furthermore it has been proven that fluorescence imaging is a useful modality to easily segment and detect acne lesions.

\section{References}

Alamdari, N., Tavakolian, K., Alhashim, M., \& Fazel-Rezai, R. (2016, May). Detection and classification of acne lesions in acne patients: A mobile application. In 2016 IEEE International Conference on Electro Information Technology (EIT) (pp. 0739-0743). IEEE.

Arifin, M. S., Kibria, M. G., Firoze, A., Amini, M. A., \& Yan, H. (2012, July). Dermatological disease diagnosis using color-skin images. In 2012 International Conference on Machine Learning and Cybernetics (Vol. 5, pp. 1675-1680). IEEE.

Becker, M., Wild, T., \& Zouboulis, C. C. (2017). Objective assessment of acne. Clinics in dermatology, 35(2), 147-155.

Borelli, C., Merk, K., Schaller, M., Jacob, K., Vogeser, M., Weindl, G., ... \& Plewig, G. (2006). In vivo porphyrin production by $\mathrm{P}$. acnes in untreated acne patients and its modulation by acne treatment. Acta dermato-venereologica, 86(4), 316-319.

Budhi, G. S., Adipranata, R., \& Gunawan, A. (2017, September). Acne Segmentation and Classification using Region Growing and Self-Organizing Map. In 2017 International Conference on Soft Computing, Intelligent System and Information Technology (ICSIIT) (pp. 78-83). IEEE.

Chang, C. Y., \& Liao, H. Y. (2013). Automatic facial spots and acnes detection system. Journal of Cosmetics, Dermatological Sciences and Applications, 3(01), 28.

Chantharaphaichi, T., Uyyanonvara, B., Sinthanayothin, C., \& Nishihara, A. (2015, March). Automatic acne detection for medical treatment. In 2015 6th International Conference of Information and Communication Technology for Embedded Systems (IC-ICTES) (pp. 1-6). IEEE.

Chen, D. H., Chang, T. R., \& Cao, R. J. (2012, August). The development of a skin inspection imaging system on an Android device. In 7th International Conference on Communications and Networking in China (pp. 653-658). IEEE. 
Analysis of segmentation methods for acne vulgaris images. Proposal of a new methodology applied to fluorescence images.

Fujii, H., Yanagisawa, T., Mitsui, M., Murakami, Y., Yamaguchi, M., Ohyama, N., ... \& Kubota, Y. (2008, August). Extraction of acne lesion in acne patients from multispectral images. In 2008 30th Annual International Conference of the IEEE Engineering in Medicine and Biology Society (pp. 4078-4081). IEEE.

Humayun, J., Malik, A. S., Belhaouari, S. B., Kamel, N., \& Yap, F. B. B. (2012, June). Localization ofacne lesionthroughtemplate matching. In 2012 4th International Conference on Intelligent and Advanced Systems (ICIAS2012) (Vol. 1, pp. 91-94). IEEE.

Khan, J., Malik, A. S., Kamel, N., Dass, S. C., \& Affandi, A. M. (2015, August). Segmentation of acne lesion using fuzzy C-means technique with intelligent selection of the desired cluster. In 2015 37th Annual International Conference of the IEEE Engineering in Medicine and Biology Society (EMBC) (pp. 3077-3080). IEEE.

Khongsuwan, M., Kiattisin, S., Wongseree, W., \& Leelasantitham, A. (2012, January). Counting number of points for acne vulgaris using UV fluorescence and image processing. In The 4th 2011 Biomedical Engineering International Conference (pp. 142-146). IEEE.

Kittigul, N., \& Uyyanonvara, B. (2016, March). Automatic acne detection system for medical treatment progress report. In 2016 7th International Conference of Information and Communication Technology for Embedded Systems (IC-ICTES) (pp. 41-44). IEEE.

Liberati, A., Altman, D. G., Tetzlaff, J., Mulrow, C., Gøtzsche, P. C., Ioannidis, J. P., ... \& Moher, D. (2009). The PRISMA statement for reporting systematic reviews and metaanalyses of studies that evaluate health care interventions: explanation and elaboration. PLoS medicine, 6(7), e1000100.

Liu, Z., \& Zerubia, J. (2013, September). Towards automatic acne detection using a MRF model with chromophore descriptors. In 21st European Signal Processing Conference (EUSIPCO 2013) (pp. 1-5). IEEE.

Lucky, A. W., Barber, B. L., Girman, C. J., Williams, J., Ratterman, J., \& Waldstreicher, J. (1996). A multirater validation study to assess the reliability of acne lesion counting. Journal of the American Academy of Dermatology, 35(4), 559-565.

Madan, S. K., Dana, K. J., \& Cula, O. (2011, December). Learning-based detection of acnelike regions using time-lapse features. In 2011 IEEE Signal Processing in Medicine and Biology Symposium (SPMB) (pp. 1-6). IEEE. 
Malik, A. S., Humayun, J., Kamel, N., \& Yap, F. B. (2014). Novel techniques for enhancement and segmentation of acne vulgaris lesions. Skin Research and Technology, 20(3), 322-331.

Malik, A. S., Ramli, R., Hani, A. F. M., Salih, Y., Yap, F. B. B., \& Nisar, H. (2014, May). Digital assessment of facial acne vulgaris. In 2014 IEEE International Instrumentation and Measurement Technology Conference (I2MTC) Proceedings (pp. 546-550). IEEE.

Maroni, G., Ermidoro, M., Previdi, F., \& Bigini, G. (2017, November). Automated detection, extraction and counting of acne lesions for automatic evaluation and tracking of acne severity. In 2017 IEEE Symposium Series on Computational Intelligence (SSCI) (pp. 1-6). IEEE.

Min, S., Kong, H. J., Yoon, C., Kim, H. C., \& Suh, D. H. (2013). Development and evaluation of an automatic acne lesion detection program using digital image processing. Skin Research and Technology, 19(1), e423-e432.

Patwardhan, S. V., Richter, C., Vogt, A., Blume-Peytavi, U., Canfield, D., \& Kottner, J. (2017). Measuring acne using Coproporphyrin III, Protoporphyrin IX, and lesionspecific inflammation: an exploratory study. Archives of dermatological research, 309(3), 159-167.

Ramli, R., Malik, A. S., Hani, A. F. M., \& Jamil, A. (2012). Acne analysis, grading and computational assessment methods: an overview. Skin research and technology, 18(1), 1-14.

Ramli, R., Malik, A. S., Hani, A. F. M., \& Yap, F. B. B. (2011a, September). Identification of acne lesions, scars and normal skin for acne vulgaris cases. In 2011 National Postgraduate Conference (pp. 1-4). IEEE.

Ramli, R., Malik, A. S., Hani, A. F. M., \& Yap, F. B. B. (2011b, December). Segmentation of acne vulgaris lesions. In 2011 International Conference on Digital Image Computing: Techniques and Applications (pp. 335-339). IEEE.

Son, T., Han, B., Jung, B., \& Nelson, J. S. (2008). Fluorescent image analysis for evaluating the condition of facial sebaceous follicles. Skin Research and Technology, 14(2), 201-207.

Williams, H. C., Dellavalle, R. P., \& Garner, S. (2012). Acne vulgaris. The Lancet, 379(9813), 361372.

Xu, D. T., Yan, J. N., Liu, W., Hou, X. X., Zheng, Y., Jiang, W. W., ... \& Wang, X. L. (2018). Is Human Sebum the Source of Skin Follicular Ultraviolet-Induced Red Fluorescence? A Cellular to Histological Study. Dermatology, 234, 43-50.

Youn, S. W., Kim, J. H., Lee, J. E., Kim, S. O., \& Park, K. C. (2009). The facial red fluorescence of ultraviolet photography: is this color due to Propionibacterium acnes or 
Analysis of segmentation methods for acne vulgaris images. Proposal of a new methodology applied to fluorescence images.

the unknown content of secreted sebum?. Skin Research and Technology, 15(2), 230236.

Zouboulis, C. C. (2014). Acne as a chronic systemic disease. Clinics in dermatology, 32(3), 389-396. 